\title{
Quantitative description of MLCT transitions in ruthenium polypyridyl complexes probed by two-photon absorption spectroscopy
}

\author{
Charles W. Stark ${ }^{1}$, M. Rammo ${ }^{1}$, K. Petritšenko ${ }^{1}$, J. Pahapill ${ }^{1}$, A. Mikhaylov ${ }^{1}$, A. Rebane ${ }^{1,2, *}$ \\ ${ }^{1}$ Keemilise ja Bioloogilise Füüsika Instituut, Tallinn 12618, Estonia \\ ${ }^{2}$ Department of Physics, Montana State University, Bozeman, USA
}

\begin{abstract}
Quantitative two-photon absorption (2PA) cross section and 2PA spectrum measurements were used to determine the molecular electric dipole change in the metal-to-ligand charge-transfer transition of ruthenium(II) tris-complexes of 2,2'-bipyridine ([Ru(bpy) $\left.]_{3}\right]^{2+}$ ) and 1,10phenanthroline $\left(\left[\mathrm{Ru}(\mathrm{phen})_{3}\right]^{2+}\right)$ in several solvents.
\end{abstract}

\section{Introduction}

Ruthenium(II) polypyridyl complexes are well studied systems with the ability to form metal-to-ligand charge-transfer (MLCT) excited states with visible light absorption. This charge-transfer makes these complexes useful for numerous applications, but also makes them sensitive to local electric fields due to the formation of a dipole moment, $\Delta \mu$.

Quantitative two-photon absorption (2PA) spectroscopy is a versatile technique that can measure changes of permanent electric dipole moment.[1,2] We investigated the 2PA spectra of $\left[\mathrm{Ru}(\mathrm{bpy})_{3}\right]^{2+}$ and $\left[\mathrm{Ru}(\text { phen })_{3}\right]^{2+}$ dissolved in water $\left(\mathrm{H}_{2} \mathrm{O}\right)$, dimethylsulfoxide (DMSO), acetonitrile (ACN), and dichloromethane (DCM), and use a two-level model of 2PA applied to the lowest-energy transitions to estimate the value of $\Delta \mu$ in different solvents.

\section{Results and Discussion}

The 2PA cross-sections over the wavelength range of $680-1020 \mathrm{~nm}$ for $\left[\mathrm{Ru}(\mathrm{bpy})_{3}\right]^{2+}$ and $\left[\mathrm{Ru}(\mathrm{phen})_{3}\right]^{2+}$ are shown as solid lines in Figure 3. Applying the two-state model of 2PA[1] to the lowest-energy transitions, we can evaluate the difference in the ground- and excited state dipole moments according to the equation:

$$
|\Delta \mu|=\frac{13650}{n^{2}+2} \sqrt{\frac{n}{\lambda} \frac{\sigma_{2 P A}(2 \lambda)}{\varepsilon_{1 P A}(\lambda)}},
$$

where $n$ is the index of refraction, $\varepsilon_{1 \mathrm{PA}}$ is the molar absorption coefficient at wavelength $\lambda$, and $\sigma_{2 \mathrm{PA}}$ is the $2 \mathrm{PA}$ cross section at twice that wavelength. The calculated $\Delta \mu$ values

\footnotetext{
* Corresponding author: arebane@montana.edu
} 
(Table 1) are in the range $5-8 \mathrm{D}$ and show a decrease with decreasing solvent polarity. Our all-optical measurements agree with previous electroabsorption measurements, $[3,4]$ but are the first to show the dipole moment solvent dependence for both complexes, which is important in their function as a charge-transfer photosensitizers.
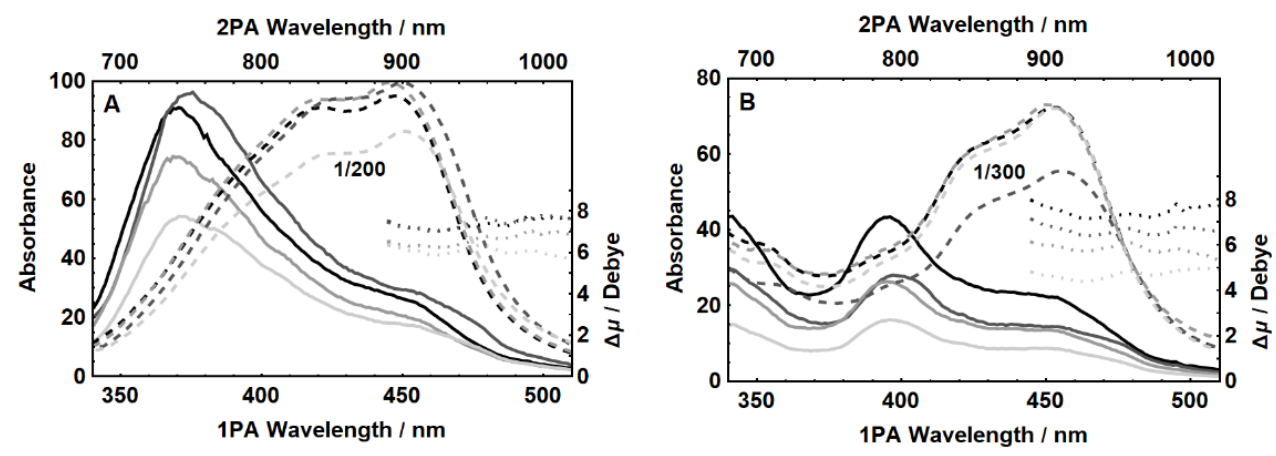

Fig 1. Absorption spectra collected for $\left[\mathrm{Ru}(\text { phen })_{3}\right]^{2+}(\mathrm{A})$ and $\left[\mathrm{Ru}(\text { bpy })_{3}\right]^{2+}$ (B) in $\mathrm{H}_{2} \mathrm{O}$ (Black), DMSO (Dark-Gray), ACN (Mid-Gray), and DCM (Light-Gray). 2PA (solid lines) are in units of Goeppert-Mayer (GM), and 1PA molar absorption coefficients $\left(\mathrm{M}^{-1} \mathrm{~cm}^{-1}\right.$, dashed lines) are scaled for comparison. The calculated dipole moment $(\Delta \mu)$ is displayed with units on the right-hand axis.

Table 1. Comparison of the 1PA molar absorption coefficient $(\varepsilon)$ and 2PA cross section $(\sigma)$ at $\lambda_{\max }$ for both complexes in the four solvents studied, as well as the relative permittivity $(\varepsilon$ r) for each solvent.

\begin{tabular}{ccccccccc}
\multirow{2}{*}{ Solvent } & \multirow{2}{*}{$\varepsilon_{\mathrm{r}}$} & \multicolumn{3}{c}{$\left[\mathrm{Ru}(\mathrm{bpy})_{3}\right]^{2+}$} & & \multicolumn{3}{c}{$\left[\mathrm{Ru}(\mathrm{phen})_{3}\right]^{2+}$} \\
\cline { 3 - 5 } \cline { 7 - 9 } & & $\varepsilon\left(\mathrm{M}^{-1} \mathrm{~cm}^{-1}\right)$ & $\sigma(\mathrm{GM})$ & $|\Delta \mu|(\mathrm{D})$ & & $\varepsilon\left(\mathrm{M}^{-1} \mathrm{~cm}^{-1}\right)$ & $\sigma(\mathrm{GM})$ & $|\Delta \mu|(\mathrm{D})$ \\
\hline $\mathrm{H}_{2} \mathrm{O}$ & 78 & $14450^{\mathrm{a}}$ & 56 & 7.4 & & $19000^{\mathrm{a}}$ & 83 & 7.4 \\
$\mathrm{DMSO}$ & 47 & $11100^{\mathrm{b}}$ & 32 & 6.6 & & $19900^{\mathrm{e}}$ & 93 & 7.4 \\
$\mathrm{CAN}$ & 36 & $14600^{\mathrm{c}}$ & 27 & 6.0 & & $19900^{\mathrm{d}}$ & 73 & 6.6 \\
$\mathrm{DCM}$ & 9 & $14400^{\mathrm{e}}$ & 26 & 4.5 & & $16600^{\mathrm{e}}$ & 54 & 6.0
\end{tabular}

${ }^{\mathrm{a}}$ ref [5], ${ }^{\mathrm{b}}$ ref [6], ${ }^{\mathrm{c}}$ ref [7], ${ }^{\mathrm{d}}$ ref [8], ${ }^{\mathrm{e}}$ ref [9].

\section{References}

1. A. Rebane, G. Wicks, M. Drobizhev, T. Cooper, A. Trummal, and M. Uudsemaa, Angew. Chem. Int. Ed., 54, 7582 (2015)

2. S. de Reguardati, J. Pahapill, A. Mikhailov, Y. Stepanenko, and A. Rebane, Opt. Express, 24, 9053 (2016)

3. L. Karki, and J. T. Hupp, Inorg. Chem. 36, 3318 (1997)

4. K. Kawamoto, Y. Tamiya, T. Storr, R.J. Cogdell, I. Kinoshita, and H. Hashimoto, J. Photochem. Photobiol. Chem. 353, 618 (2018)

5. K. Kalyanasundaram, Coord. Chem. Rev. 46, 159 (1982)

6. G. A. Heath, L. J. Yellowlees, and P. S. Braterman, J. Chem. Soc. - Chem. Commun., 0, 287 (1981)

7. A. Yoshimura, M. Hoffman, and H. Sun, J. Photochem. Photobiol. Chem. 70, 29 (1993)

8. R. J. Staniewicz, R. F. Sympson, and D. G. Hendricker, Inorg. Chem., 16, 2166 (1977)

9. J. V. Caspar, and T. J. Meyer, Inorg. Chem., 22, 2444 (1983) 